\title{
Produtividade de cebola em cultivo orgânico utilizando composto à base de dejetos de suínos
}

\author{
Sanzio M Vidigal' ${ }^{1}$ Maria Aparecida N Sediyama ${ }^{1}$; Marinalva W Pedrosa ${ }^{2}$; Marlei R dos Santos ${ }^{1}$ \\ ${ }^{1}$ EPAMIG-Unidade Regional Zona da Mata, Vila Gianetti, 46/47, Campus da UFV, 36571-000 Viçosa-MG; ${ }^{2}$ EPAMIG-Unidade Regional \\ Centro Oeste, C. Postal 295, 35701-970 Prudente de Morais-MG; sanziomv@epamig.br; marians@epamig.ufv.br; marinalva@epamig. \\ br; marleirs@yahoo.com.br
}

\section{RESUMO}

O trabalho foi conduzido em Oratórios-MG com objetivo de avaliar o estado nutricional, a produtividade e a extração de nutrientes pela cebola, cv. CNPH 6400, em sistema orgânico, submetida a doses de composto orgânico. $\mathrm{O}$ delineamento experimental foi de blocos ao acaso, com quatro repetições, e os tratamentos consistiram de cinco doses de composto orgânico à base de dejeto sólido de suíno $\left(0 ; 10 ; 20 ; 30\right.$ e $\left.60 \mathrm{t} \mathrm{ha}^{-1}\right)$. As mudas foram transplantadas aos 49 dias após a semeadura (DAS). A colheita ocorreu aos 168 DAS e a produtividade máxima de bulbos comercializáveis foi de $60,3 \mathrm{t} \mathrm{ha}^{-1}$, estimada com a aplicação de $43,4 \mathrm{t} \mathrm{ha}^{-1}$ de composto. A máxima produção de bulbos da classe 3 foi de $33,3 \mathrm{t} \mathrm{ha}^{-1}$, estimada com $32 \mathrm{t} \mathrm{ha}^{-1}$ de composto. Na classe 4 a produção foi crescente e na classe 2 a resposta decresceu com as doses. A produção máxima de matéria seca de bulbos foi estimada em $6.271 \mathrm{~kg} \mathrm{ha}^{-1}$ com $46 \mathrm{t} \mathrm{ha}^{-1}$ de composto. Com a aplicação de $43,4 \mathrm{t} \mathrm{ha}^{-1}$ de composto orgânico, a exportação de nutrientes pelos bulbos corresponde a $116,65 \mathrm{~kg} \mathrm{ha}^{-1}$ de N; 22,71 $\mathrm{kg} \mathrm{ha}^{-1}$ de P; 117,65 kg ha ${ }^{-1}$ de $\mathrm{K} ; 19,47 \mathrm{~kg} \mathrm{ha}^{-1}$ de Ca; $8,31 \mathrm{~kg} \mathrm{ha}^{-1}$ de Mg e $19,94 \mathrm{~kg} \mathrm{ha}^{-1}$ de S. A aplicação de $43 \mathrm{tha}^{-1} \mathrm{de}$ composto orgânico é suficiente para a obtenção de bulbos com ótima qualidade e produtividade. A cv. CNPH 6400 pode ser recomendada para o cultivo em sistema orgânico na região.

Palavras-chave: Allium cepa, adubação orgânica, composição mineral.

\begin{abstract}
Onion yield in organic system using organic compost of swine manure

The study was carried out in Oratórios, Minas Gerais State, Brazil, with objective of evaluating the plant nutritional state, yield and nutrients extraction by onion, cv. CNPH 6400, in organic system, submitted to rates of organic compost of swine manure. The experiment was arranged in a randomized block design, with four replications and the treatments consisted of five rates of organic compost $\left(0,10 ; 20 ; 30\right.$ and $\left.60 \mathrm{tha}^{-1}\right)$. The seedlings were transplanted on the $49^{\text {th }}$ day after the sowing (DAS). Plants were harvested on 168 DAS and the maximum yield of marketable bulbs was $60.3 \mathrm{t}$ $\mathrm{ha}^{-1}$, obtained with $43.4 \mathrm{t} \mathrm{ha}^{-1}$ of organic compost. The maximum yield of bulbs Class 3 was $33.346 \mathrm{~kg} \mathrm{ha}^{-1}$, obtained with $32 \mathrm{t} \mathrm{ha}^{-1}$ of organic compost. In the Class 4 the yield was increasing and the Class 2 presented decreasing with the rates. The maximum yield of dry matter of bulbs was of $6.271 \mathrm{~kg} \mathrm{ha}^{-1}$, obtained with $46 \mathrm{tha}^{-1}$. With $43 \mathrm{t} \mathrm{ha}^{-1}$ of organic compost, the export of nutrients by bulbs would be $116.65 \mathrm{~kg} \mathrm{ha}^{-1}$ of $\mathrm{N} ; 22.71 \mathrm{~kg} \mathrm{ha}^{-1}$ of P; $117.65 \mathrm{~kg} \mathrm{ha}^{-1}$ of $\mathrm{K} ; 19.47 \mathrm{~kg} \mathrm{ha}^{-1}$ of Ca; $8.31 \mathrm{~kg} \mathrm{ha}^{-1}$ of $\mathrm{Mg}$ and $19.94 \mathrm{~kg} \mathrm{ha}^{-1}$ of $\mathrm{S}$. The application of $43 \mathrm{t} \mathrm{ha}^{-1}$ of organic compost is enough to obtain onion bulbs with great quality and yield. The cv. CNPH 6400 can be recommended for the organic system.
\end{abstract}

Keywords: Allium cepa, organic fertilization, mineral composition, yield.

(Recebido para publicação em 1 de dezembro de 2008; aceito em 18 de janeiro de 2010)

(Received on December 1, 2008; accepted on January 18, 2010)

A cebola é uma hortaliça de grande importância econômica, sendo a terceira mais cultivada no mundo, ultrapassada apenas pelo tomate e batata. A área de produção no Brasil é de 70.000 ha ano $^{-1}$, com rendimento, nos últimos anos, próximo de $19 \mathrm{t} \mathrm{ha}^{-1}$, mas cultivos bem conduzidos têm rendimentos entre 40 e $60 \mathrm{t} \mathrm{ha}^{-1}$ ou até mesmo superior (Vidigal et al., 2007).

O cultivo da cebola em sistema orgânico vem ganhando espaço nas regiões produtoras. Em Santa Catarina, o sistema de produção agroecológico já aparece nos estudos de mercado, com rendimento de $10 \mathrm{t} \mathrm{ha}^{-1}$, a um custo de R\$ 3.256,00/ha (Camargo Filho \& Al- ves, 2005). Entretanto, poucos estudos, com este sistema de produção têm sido realizados (Leal, 2001; Pereira et al., 2002). Mais recentemente, Rodrigues et al. (2006) comparam 16 genótipos de cebola no cultivo convencional e em sistema orgânico, concluindo ser possível produzir cebola em sistema orgânico com os genótipos avaliados para o mercado consumidor de cebola in natura, enquanto no sistema convencional a cebola seria mais adequada para a indústria. Outros estudos foram realizados visando a geração de tecnologias de controle de doenças (Gonçalves et al., 2004a) e de pragas (Gonçalves et al., 2004b).
Com a elevação do preço dos fertilizantes minerais nos últimos anos a procura por fontes alternativas de nutrientes tem aumentado. Considerando a grande disponibilidade de dejeto de suínos na região do Vale do Piranga, na Zona da Mata mineira, formas de utilização desses adubos orgânicos, especialmente dos estercos de suínos e dos compostos orgânicos têm sido consideradas muito importantes para melhoria dos sistemas de produção. Assim, a geração de tecnologias para a recomendação de doses de adubo orgânico é uma necessidade para o sistema de produção orgânico de cebola. Este trabalho teve por objetivo avaliar o estado nutricional, a extração 
de nutrientes e a produtividade da cebola, cv. CNPH 6400, cultivada no sistema orgânico e submetida a doses de composto orgânico produzido com dejeto sólido de suínos.

\section{MATERIAL E MÉTODOS}

$\mathrm{O}$ experimento foi realizado na $\mathrm{Fa}-$ zenda Experimental Vale do Piranga, pertencente à EPAMIG, localizada no município de Oratórios, Zona da Mata de Minas Gerais, no período de maio a outubro/2005, utilizando-se a cebola, cv. CNPH 6400. Aárea experimental localizada dentro da Horta de Pesquisa para o cultivo orgânico encontra-se numa fase de transição. O solo utilizado, Argissolo Vermelho-Amarelo câmbico, fase terraço, textura argilosa, apresentou, na camada de 0 a $20 \mathrm{~cm}$ de profundidade, as características: $\mathrm{pH}$ (água 1:2,5) $=5,4$; matéria orgânica $=28 \mathrm{~g} \mathrm{~kg}^{-1} ; \mathrm{P}=14,4$ $\mathrm{mg} \mathrm{dm}^{-3} ; \mathrm{K}=155 \mathrm{mg} \mathrm{dm}^{-3} \mathrm{e}$, em $\mathrm{cmol}_{\mathrm{c}}$ $\mathrm{dm}^{-3}, \mathrm{Ca}^{2+}=1,7 ; \mathrm{Mg}^{2+}=0,5 ; \mathrm{Al}^{3+}=0,0$; $\mathrm{H}+\mathrm{Al}=1,98 ; \mathrm{SB}=2,60 ; \mathrm{CTC}(\mathrm{t})=2,60$; $\mathrm{CTC}(\mathrm{T})=4,58 ; \mathrm{V}=57 \%$.

Os tratamentos consistiram de cinco doses de composto orgânico $(0 ; 10 ; 20$; 30 e $60 \mathrm{t} \mathrm{ha}^{-1}$ ) e foram aplicados sete dias antes do transplante das mudas. $\mathrm{O}$ delineamento foi em blocos casualizados, com quatro repetições. A semeadura foi realizada em bandejas de isopor de 200 células em 11 de maio de 2005 e o transplante ocorreu 49 dias após a semeadura (DAS), no espaçamento de $0,10 \mathrm{~m}$ x 0,25 m. A parcela foi constituída de quatro linhas com 30 plantas cada e a parcela útil constou de 48 plantas das duas linhas centrais.

O composto orgânico foi produzido com dejeto sólido de suínos, proveniente de separação em peneira mecânica, associado ao bagaço (bagacilho) de canade-açúcar de forma a apresentar $\mathrm{C} / \mathrm{N}$ inicial de 30/1. Após o processo (120 dias), o composto orgânico apresentou as seguintes características: $\mathrm{pH}$ (água) $=$ 5,4; $\mathrm{N}=22,4 \mathrm{~g} \mathrm{~kg}^{-1} ; \mathrm{P}=6,7 \mathrm{~g} \mathrm{~kg}^{-1} ; \mathrm{K}=$ $3,3 \mathrm{~g} \mathrm{~kg}^{-1} ; \mathrm{Ca}=13,5 \mathrm{~g} \mathrm{~kg}^{-1} ; \mathrm{Mg}=2,2 \mathrm{~g}$ $\mathrm{kg}^{-1}$ e S = 2,6 $\mathrm{g} \mathrm{kg}^{-1} ; \mathrm{Zn}=57,0 \mathrm{mg} \mathrm{kg}^{-1}$; $\mathrm{Cu}=56,0 \mathrm{mg} \mathrm{kg}^{-1} ; \mathrm{B}=31 \mathrm{mg} \mathrm{kg}^{-1} ; \mathrm{Fe}$ $=14.801 \mathrm{mg} \mathrm{kg}^{-1}$ e $\mathrm{Mn}=410 \mathrm{mg} \mathrm{kg}^{-1}$; C.Org. $=243,3 \mathrm{~g} \mathrm{~kg}^{-1}$ e C/N =10,86.

A irrigação foi realizada por asper- são convencional, as capinas foram feitas manualmente e foram realizadas aplicações de Calda Viçosa a cada 15 dias. Aos 75 DAS foi feita análise foliar para avaliação do estado nutricional das plantas de cebola (Vidigal, 2000), sendo retiradas cinco folhas jovens totalmente desenvolvidas, aleatoriamente, em cada parcela. As amostras, após a secagem em estufa de circulação forçada de ar, foram moídas e determinaram-se na matéria seca, os teores de N-orgânico pelo reagente de Nessler, após digestão sulfúrica, P pelo método da Vitamina C, $\mathrm{K}$ por fotometria de chama, $\mathrm{Ca}$ e $\mathrm{Mg}$ por espectrofotômetro de absorção atômica e S por turbidimetria, após digestão nítrico perclórica (Embrapa, 1997).

A colheita foi realizada, aos 168 DAS, quando mais de $60 \%$ das plantas encontravam-se estaladas. As plantas permaneceram cinco dias no campo para efetuar a cura. Em seguida, procedeu-se a classificação dos bulbos sem defeitos em cinco classes comerciais, de acordo com o maior diâmetro transversal, onde $1=$ diâmetro transversal menor que 35 $\mathrm{mm} ; 2=35$ a $50 \mathrm{~mm} ; 3=50$ a $70 \mathrm{~mm}$; $4=70$ a 90 mm e $5=$ diâmetro transversal maior que $90 \mathrm{~mm}$ (Brasil, 1995). A produção comercial foi avaliada pelo somatório das massas dos bulbos das classes 2, 3, 4 e 5 e a não comercial correspondeu ao somatório das massas dos bulbos da classe 1 e dos bulbos desqualificados, devido a defeitos, como: podridões, má-formação, rachaduras e danos causados por pragas. A produção total foi obtida pelo somatório das classes comercial e não comercial. Foi calculado o incremento relativo na produtividade advindo da adubação orgânica (IRPAO). Para tal, utilizou-se a diferença entre a produtividade máxima de bulbos comercializáveis (PM), em kg $\mathrm{ha}^{-1} \mathrm{e}$ a produtividade de bulbos comercializáveis com a dose zero (PBC zero), dividida pela dose de composto orgânico necessária para obter a $\mathrm{PM}$, por meio da fórmula: IRPAO = (PM - PBC zero $) /$ (Dose para PM).

Após a classificação foi retirada uma amostra de 10 bulbos comercializáveis das classes 3 e 4, na qual foi avaliado o teor de sólidos solúveis totais (Brix) no extrato de bulbos comerciais, por meio de um refratômetro digital marca
ATAGO, modelo PR-101, escala 0 a 45\% Brix. Nesta mesma amostra, avaliou-se o teor de matéria seca, após secagem em estufa com circulação forçada de ar à temperatura de $65-70^{\circ} \mathrm{C}$, durante $72 \mathrm{~h}$. Após a secagem, as amostras foram moídas e determinaram-se os teores de macronutrientes (N, P, K, Ca, Mg e S) e a quantidade de nutrientes exportados pelos bulbos de cebola.

Os dados foram submetidos às análises de variância e de regressão, além do teste de Tukey a 5\% de probabilidade. Os modelos de regressão foram escolhidos baseados na ocorrência biológica e na significância dos coeficientes de regressão tendo como variável independente as doses de composto orgânico aplicadas.

\section{RESULTADOS E DISCUSSÃO}

A produtividade máxima de bulbos comercializáveis foi de $60,3 \mathrm{tha}^{-1}$, estimada com a aplicação de 43,4 $\mathrm{t} \mathrm{ha}^{-1} \mathrm{de}$ composto orgânico (Figura 1), sendo produzidos $358,7 \mathrm{~kg} \mathrm{ha}^{-1} \mathrm{dia}^{-1}$ com o ciclo cultural de 168 dias. A produtividade total máxima foi estimada em 61,5 t ha-1, com a aplicação de 43,8 t $\mathrm{ha}^{-1}$ de composto orgânico (Figura 1), demonstrando que o cultivo orgânico de cebola foi eficiente na produção de bulbos de qualidade, uma vez que a produção de bulbos não comercializáveis foi muito baixa. A produtividade obtida superou, em muito, a média brasileira para cultivos convencionais que é de $17 \mathrm{t} \mathrm{ha}^{-1}$ (Vilela et al., 2005), bem como as obtidas por Pereira et al. (2002), de $22 \mathrm{t} \mathrm{ha}^{-1}$, com $20 \mathrm{t} \mathrm{ha}^{-1} \mathrm{de}$ esterco bovino para a mesma cultivar, porém numa região de clima mais frio no Sul de Minas Gerais.

Os resultados obtidos demonstram o potencial produtivo da cultivar $\mathrm{CNPH}$ 6400, para o sistema orgânico de produção. Apesar de poucos trabalhos, no sistema orgânico, a resposta tem sido influenciada pela cultivar utilizada, conforme observado por Leal (2001), onde a aplicação de 2,0 kg de cama de frango por metro linear de canteiro, equivalente a $16,7 \mathrm{t} \mathrm{ha}^{-1}$, proporcionou produtividades iguais a 39,7 $\mathrm{t} \mathrm{ha}^{-1}$ (AlfaTropical); 25 t ha $^{-1}$ (Red Creole) e 22,5 t ha-1 (Baia Periforme). 


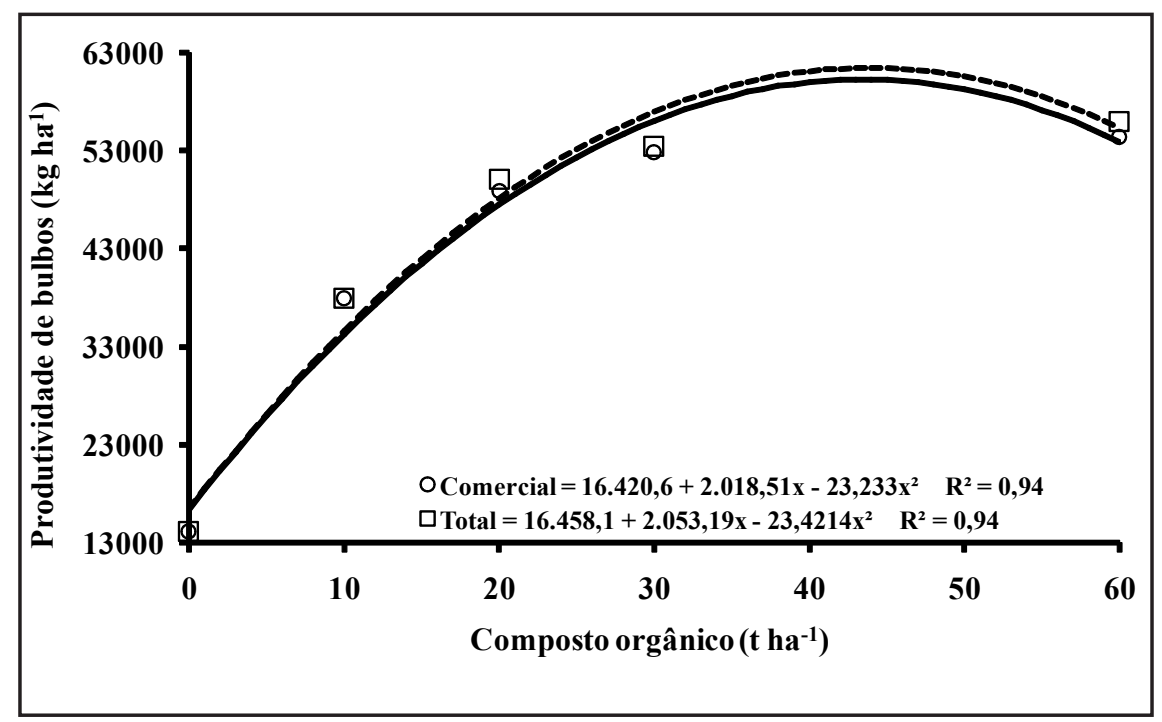

Figura 1. Produtividade de bulbos comercial e total de cebola, cv. CNPH 6400, cultivada no sistema orgânico, em função da aplicação de doses de composto orgânico à base de dejeto sólido de suínos (commercial and total yield of onion bulbs, cv. CNPH 6400, in organic system, depending on the rate of organic compost of swine manure). Oratórios, EPAMIG, 2005 .

Com a aplicação de 27,3 $\mathrm{t} \mathrm{ha}^{-1}$ de composto orgânico à base de dejeto sólido de suínos estima-se a produtividade de 54,2 $\mathrm{t} \mathrm{ha}^{-1}$ de bulbos equivalentes a $90 \%$ da produção máxima $(\mathrm{PM})$ de bulbos comercializáveis (Figura 1). Esta quantidade de adubo orgânico é inferior à recomendada por Vidigal et al. (2002), no cultivo convencional, para Minas Gerais, que é de $40 \mathrm{t} \mathrm{ha}^{-1}$ de adubo orgânico mais adubo mineral, de acordo com os resultados da análise de solo. A aplicação de $40 \mathrm{t} \mathrm{ha}^{-1}$ do composto orgânico, para as condições desse trabalho, estima-se a produtividade de bulbos comercializáveis igual a $60 \mathrm{t}$ $\mathrm{ha}^{-1}$, demonstrando ser possível alcançar altas produtividades de cebola sem a utilização de adubo mineral.

Entre as classes de bulbos comercializáveis, a classe 3 alcança maiores preços de mercado. A máxima produtividade de bulbos da classe 3 foi de 33,3 $\mathrm{t} \mathrm{ha}^{-1}$, estimada com a aplicação de $32 \mathrm{t}$ $\mathrm{ha}^{-1}$ de composto orgânico ( $\hat{\mathrm{Y}}=6660+$ $\left.9405,66 \sqrt{x}-828,76 x, R^{2}=0,95\right)$. Essa classe representou a maior proporção de bulbos comercializáveis para todas as doses de composto orgânico aplicadas, não havendo diferença entre as doses, mas superior à testemunha (Tabela 1).

Não houve ajuste de equações para os dados de produtividade nas classes 2 e 4 , sendo que na classe 4 a produtivida- da classe 1 (não comercial) apresentou a mesma tendência da classe 2, ou seja, maior produtividade foi obtida na testemunha (Tabela 1). A produtividade de bulbos da classe 5 só foi observada no tratamento com a aplicação de $30 \mathrm{t}$ ha $^{-1}$ de composto orgânico (dados não apresentados).

$\mathrm{O}$ incremento relativo na produtividade comercial advindo da adubação com o composto orgânico (IRPAO) foi igual a $1,1 \mathrm{t}$ de cebola por tonelada de composto orgânico aplicado.

Quanto à produtividade de matéria seca, não houve diferença significativa entre tratamentos no conteúdo de umidade dos bulbos. O percentual de matéria seca nos bulbos variou de 9,9\% na testemunha a $10,8 \%$ na maior dose de composto (60 t ha-1). No entanto, a produtividade máxima de matéria seca foi estimada em 6,3 $\mathrm{tha}^{-1}$ com a aplicação de $46 \mathrm{t} \mathrm{ha}^{-1}$ de composto orgânico (Figura 2), dose muito próxima àquela observada para a máxima produção comercial.

Além da matéria seca, é desejável para a indústria a obtenção de bulbos com maior conteúdo de sólidos solúveis, pelo maior rendimento industrial. A pungência da cebola está diretamente relacionada ao teor de sólidos solúveis totais (Moretti \& Durigan, 2002), que é uma característica intrínseca de cada cultivar, mas que pode variar com as condições edafoclimáticas do local de cultivo e com o manejo da lavoura (Oliveira, 2004). O teor de sólidos solúveis

Tabela 1. Produtividade de bulbos de cebola, cv. CNPH 6400, por classe, cultivada no sistema orgânico, em função da aplicação de doses de composto orgânico à base de dejeto sólido de suínos (onion bulbs yield, cv. CNPH 6400, by class, in organic system, depending on the rate of organic compost of swine manure). Oratórios, EPAMIG, 2005.

\begin{tabular}{ccccc}
\hline $\begin{array}{c}\text { Doses de com- } \\
\text { posto }\left(\mathbf{t ~ h a}^{-1}\right)\end{array}$ & $\mathbf{4}$ & $\mathbf{3}$ & $\mathbf{2}$ & $\mathbf{1}$ \\
\cline { 2 - 5 } & $\mathbf{4}$ & $6,1 \mathrm{~b}$ & $8,0 \mathrm{a}$ & $1,4 \mathrm{a}$ \\
0 & $0,0 \mathrm{c}$ & $30,9 \mathrm{a}$ & $3,7 \mathrm{~b}$ & $0,1 \mathrm{~b}$ \\
10 & $3,3 \mathrm{bc}$ & $30,1 \mathrm{a}$ & $1,7 \mathrm{bc}$ & $0,1 \mathrm{~b}$ \\
20 & $17,1 \mathrm{ab}$ & $32,6 \mathrm{a}$ & $1,7 \mathrm{bc}$ & $0,0 \mathrm{~b}$ \\
30 & $17,8 \mathrm{ab}$ & $30,4 \mathrm{a}$ & $0,6 \mathrm{c}$ & $0,0 \mathrm{~b}$ \\
60 & $23,4 \mathrm{a}$ & 12,6 & 37,1 & 148,6 \\
\hline $\mathrm{CV}(\%)$ & 61,3 & &
\end{tabular}

${ }^{1}$ Classe 4: 70 a $90 \mathrm{~mm}$; classe 3: 50 a $70 \mathrm{~mm}$; classe 2: 35 a $50 \mathrm{~mm}$ e classe 1: bulbos menores que $35 \mathrm{~mm}$ de diâmetro transversal (class 4: 70 to $90 \mathrm{~mm}$; class 3: 50 to $70 \mathrm{~mm}$; class 2: 35 to $50 \mathrm{~mm}$ and class 1: smaller bulbs than $35 \mathrm{~mm}$ of transversal diameter); Médias seguidas de mesma letra nas colunas não diferem entre si, pelo teste Tukey, $\mathrm{p} \leq 0,05$ (means followed by same letter in the column, did not differ from each other, Tukey's test, $p \leq 0,05$ ). 


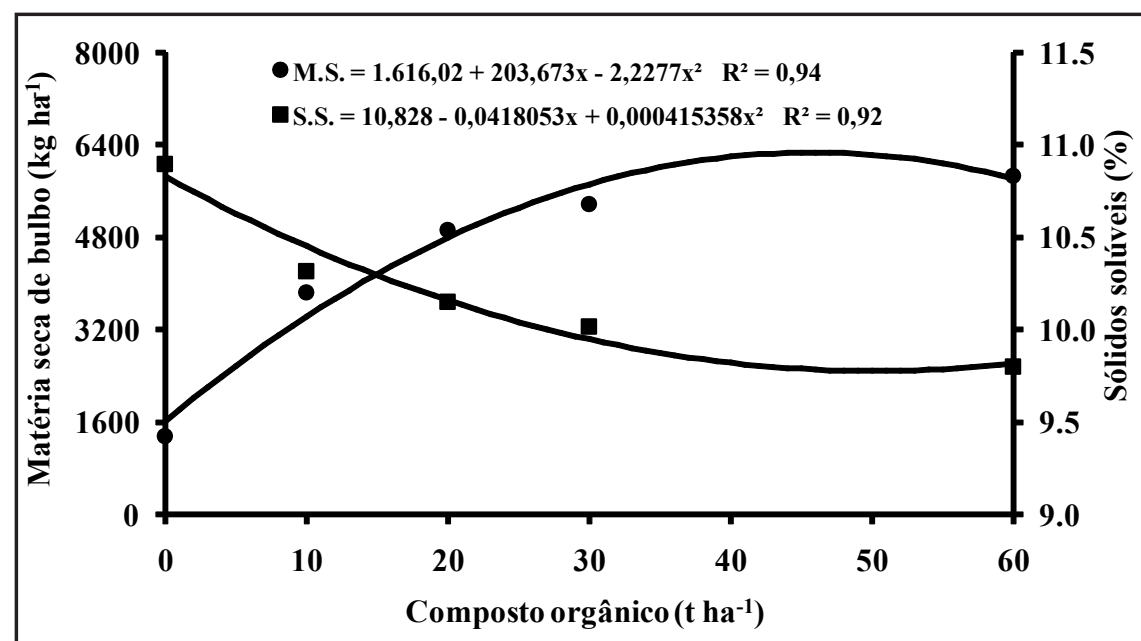

Figura 2. Produtividade de matéria seca (MS) e teor de sólidos solúveis (SS) de bulbos comercializáveis de cebola, cv. CNPH 6400, cultivada no sistema orgânico, em função da aplicação de doses de composto orgânico à base de dejeto sólido de suínos (dry matter yield (MS) and soluble solids content (SS) of commercial onion bulbs, cv. CNPH 6400, in organic system, depending on the rate of organic compost of swine manure). Oratórios, EPAMIG, 2005.

(Brix) reduziu com o aumento das doses de composto à base de dejeto sólido de suínos, alcançando o mínimo de 9,77, estimado com a aplicação de 50 tha $^{-1}$ de composto orgânico (Figura 2).

Os teores de $\mathrm{P}, \mathrm{Ca}, \mathrm{Mg}$ e $\mathrm{S}$ na matéria seca das folhas de cebola não foram influenciados pelas doses de composto orgânico aplicado. Uma das razões para esta resposta nos teores foliares de $\mathrm{Ca}$, $\mathrm{Mg}$ e S pode ser a presença destes nutrientes na Calda Viçosa aplicada como reduziram com a aplicação das doses de composto orgânico, sendo observado o maior teor foliar de $\mathrm{K}$ na matéria seca de plantas da testemunha, mas em todos os tratamentos os teores foliares estavam dentro da faixa adequada para plantas de cebola (Tabela 2).

Os teores foliares de $\mathrm{Ca}, \mathrm{Mg}$ e S não apresentaram diferença significativa entre os tratamentos. Para os teores foliares $\mathrm{de} \mathrm{Ca}$, a testemunha e o tratamento com a aplicação de 60 t ha ${ }^{-1}$ de composto orgânico estavam na faixa adequada, mas estes teores ficaram abaixo da faixa nos demais tratamentos. Os teores foliares de $\mathrm{S}$ estavam na faixa não adequada ao desenvolvimento da cebola em todos os tratamentos (Tabela 2). No entanto, em função do rendimento e do desenvolvimento das plantas de cebola pode-se considerar que as plantas estavam em bom estado nutricional para o cultivo orgânico.

Na colheita, os bulbos comercializáveis exportaram o máximo de 119,11 $\mathrm{kg} \mathrm{ha}^{-1}$ de N; 22,85 $\mathrm{kg} \mathrm{ha}^{-1}$ de P; 118,18 $\mathrm{kg} \mathrm{ha}^{-1}$ de K; 19,53 $\mathrm{kg} \mathrm{ha}^{-1}$ de Ca; 8,39 $\mathrm{kg} \mathrm{ha}^{-1} \mathrm{de} \mathrm{Mg}$ e $21,76 \mathrm{~kg} \mathrm{ha}^{-1}$ de S, estimados com a aplicação de $51,47,47$, 46, 48 e 60 t ha ${ }^{-1}$ de composto orgânico à base de dejeto sólido de suínos, respectivamente (Figura 3). Considerando a aplicação de $43 \mathrm{t} \mathrm{ha}^{-1}$ de composto orgânico, dose para máxima produção de bulbos comercializáveis, a exportação de nutrientes para uma população de 400.000 plantas/ha foi de $116,65 \mathrm{~kg}$ $\mathrm{ha}^{-1}$ de N; 22,71 kg ha ${ }^{-1}$ de P; $117,65 \mathrm{~kg}$ $\mathrm{ha}^{-1}$ de K; $19,47 \mathrm{~kg} \mathrm{ha}^{-1}$ de Ca; 8,31 kg ha $^{-1}$ de Mg e 19,94 kg ha- ${ }^{-1}$ de S.

Os resultados obtidos demonstram que a aplicação de cerca de $43 \mathrm{t} \mathrm{ha}^{-1}$ de composto orgânico à base de dejeto sólido de suínos é suficiente para a produção de bulbos de cebola com ótima qualidade e produtividade em sistema orgânico. A cv. CNPH 6400 apresentou bom desempenho produtivo e estado nutricional satisfatório podendo ser recomendada para o cultivo em sistema orgânico na região.

\section{AGRADECIMENTOS}

À FAPEMIG pelo auxílio financeiro concedido para a realização deste trabalho e pelas bolsas BIPDT. 


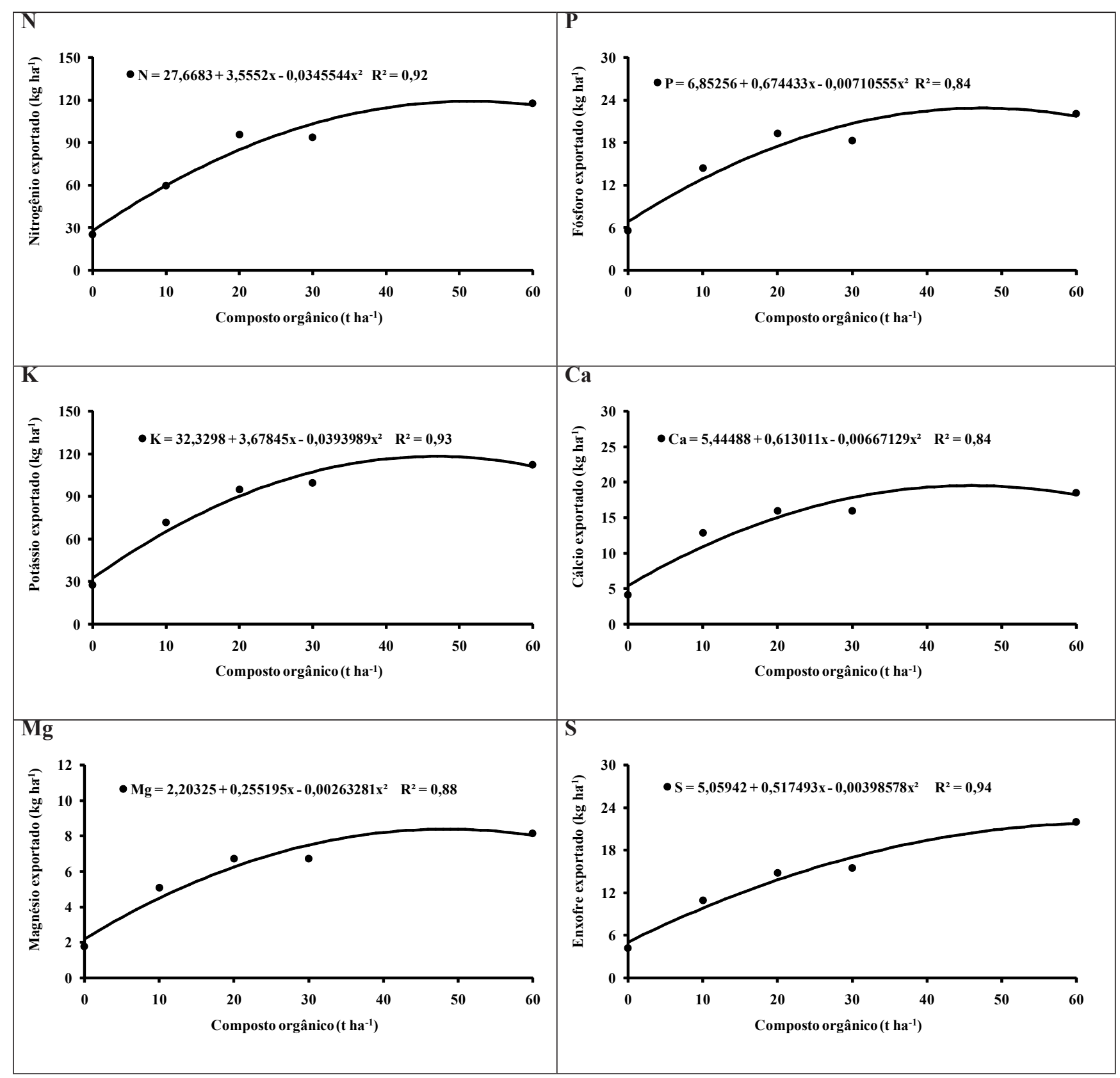

Figura 3. Quantidades de N, P, K, Ca, Mg e S exportadas por bulbos comercializáveis de cebola, cv. CNPH 6400, cultivada no sistema orgânico, em função da aplicação de doses de composto orgânico à base de dejeto sólido de suínos $(\mathrm{N}, \mathrm{P}, \mathrm{K}, \mathrm{Ca}, \mathrm{Mg}$ and $\mathrm{S}$ exported by commercial onion bulbs, cv. CNPH 6400, in organic system, depending on the rate of organic compost of swine manure). Oratórios, EPAMIG, 2005.

\section{REFERÊNCIAS}

BRASIL. 1995. Ministério da Agricultura e Reforma Agrária. Portaria Ministerial n. ${ }^{\circ} 529$, de 18 de agosto de 1995.

CALDWELL JON; SUMNER ME; VAVRINA CS. 1994. Development and testing of preliminary foliar DRIS norms for onions. HortScience 29: 1501-1504.

CAMARGO FILHO WP; ALVES HS. 2005. Produção de cebola no Mercosul: aspectos tecnológicos e integração de mercado no Brasil e na Argentina. Informações Econômicas 35: 7-17.

EMBRAPA. 1997. Manual de métodos de análises de solos. Rio de Janeiro: Embrapa. 212p. (Documentos, 1).

GONÇALVES PAS; SILVA CRS; BOFF P. 2004a. Incidência do míldio em cebola sob adubação mineral e orgânica. Horticultura Brasileira 22: 538-542.

GONÇALVES PAS; WERNER H; DEBARBA JF. 2004b. Avaliação de biofertilizantes, extratos vegetais e diferentes substâncias alternativas no manejo de tripes em cebola em sistema orgânico. Horticultura Brasileira 22: 659-662.

JONES JUNIOR JB; WOLF B; MILLS HA. 1991. Plant analysis handbook: a practical sampling, preparation, analysis and interpretation guide. Athens: Micro-Macro, 213p.
LEAL MAA. 2001. Desempenho de três cultivares de cebola, em cultivo orgânico, na Região Médio Paraíba do Estado do Rio de Janeiro. Horticultura Brasileira 19: Suplemento CDROM.

MORETTICL;DURIGANJF. 2002. Processamento de cebola. Informe Agropecuário 23: 99-104.

OLIVEIRA VR. 2004. Cebola doce. Horticultura Brasileira 22: Contracapa.

PEREIRA AJ; SOUZA RJ; PEREIRA WR. 2002. Efeito de diferentes doses de esterco de galinha e de curral sobre a produção de cebola. Horticultura Brasileira 20: Suplemento CDROM.

REUTER DJ; ROBINSON JB. 1988. Plant analysis: an interpretation manual. Melbourne: 
Inkata Press. 218p.

RODRIGUES GB; NAKADA PG; SILVA DJH; DANTAS GG; SANTOS RRH; GAVA JD. 2006. Desempenho de cultivares de cebola nos sistemas orgânico e convencional. Horticultura Brasileira 24: 206-209.

TRANI PE; RAIJ B. 1996. Hortaliças. In: RAIJ B; CANTARELLA H; QUAGGIO JA; FURLANI AMC. Recomendações de adubação e calagem para o Estado de São
Paulo. 2ed. Campinas: Instituto Agronomico/ Fundação IAC: 157-185.

VIDIGAL SM. 2000. Adubação nitrogenada de cebola irrigada cultivada no verão - Projeto Jaíba, Norte de Minas Gerais. Viçosa: UFV. 136p. (Tese doutorado).

VIDIGAL SM; PEREIRA PRG; PACHECO DD. 2002. Nutrição mineral e adubação de cebola. Informe Agropecuário 23: 36-50. VIDIGAL SM; COSTA EL; CIOCIOLA JÚNIOR
AI. 2007. Cebola (Allium cepa L.). In: PAULA JÚNIOR TJ; VENZON M (org). 101 Culturas - Manual de Tecnologias Agrícolas. Belo Horizonte: EPAMIG. p.243-252.

VILELA NJ; MAKISHIMA N; OLIVEIRA VR; COSTA ND; MADAIL JCM; CAMARGO FILHO WP; BOEING G; MELO PCT. 2005. Desafios e oportunidades para o agronegócio da cebola no Brasil. Horticultura Brasileira 23: 1029-1033. 